\title{
Application of PCR ribotyping and tDNA-PCR for Klebsiella pneumoniae identification
}

\author{
Ana Catarina S Lopes/ ${ }^{+}$, Juliana Falcão Rodrigues, Maysa BM Clementino*, \\ Catia AC Miranda*, Ana Paula A Nascimento*, Marcos Antônio de Morais Júnior**
}

\begin{abstract}
Departamento de Medicina Tropical, Laboratório de Imunopatologia Keizo Asami, Universidade Federal de Pernambuco, Av. Prof. Morais Rego s/n, 50732-970 Recife, PE, Brasil *Departamento de Microbiologia, Instituto Nacional de Controle de Qualidade em Saúde-Fiocruz, Rio de Janeiro, RJ, Brasil **Departamento de Genética, Universidade Federal de Pernambuco, Recife, PE, Brasil
\end{abstract}

$P C R$ analysis of $16 S-23 S$ internal transcribed spacer (PCR ribotyping) and tRNA intergenic spacer (tDNA$P C R$ ) were evaluated for their effectiveness in identification of clinical strains of Klebsiella pneumoniae and differentiation with related species. For this purpose both methods were applied to forty-three clinical isolates biochemically identified as $\mathrm{K}$. pneumoniae subsp. pneumoniae isolated from patients clinical specimens attended at five hospitals in three Brazilian cities. References strains of K. pneumoniae subsp. pneumoniae, K. pneumoniae subsp. ozaenae, K. oxytoca, K. planticola and Enterobacter aerogenes were also analyzed. Both PCR methods showed specific patterns for each species. A conserved PCR ribotype pattern was observed for all clinical $\mathrm{K}$. pneumoniae isolates, while differing from other related analyzed species. tDNA-PCR revealed five distinct patterns among the K. pneumoniae clinical isolates studied, demonstrating a predominant group with 90,6\% of isolates presenting the same pattern of $\mathrm{K}$. pneumoniae type strain. Both PCR-based methods were not able to differentiate K. pneumoniae subspecies. On the basis of the results obtained, both methods were efficient to differentiate the Klebsiella species analyzed, as well as E. aerogenes. Meanwhile tDNA-PCR revealed different tRNA arrangements in K. pneumoniae, suggesting intra-species heterogeneity of their genome organization, the polymorphism of the intergenic spacers between $16 \mathrm{~S}$ and $23 \mathrm{~S}$ rRNA genes appears to be highly conserved whithin K. pneumoniae clinical isolates, showing that PCR ribotyping can be an useful tool for identification of $\mathrm{K}$. pneumoniae isolates.

Key words: K. pneumoniae - PCR ribotyping - tDNA-PCR.

Klebsiella pneumoniae is a microorganism able to infect debilitated and immunocompromised patients, especially those with risk factors to acquire hospital infections. Due to the extensive spread of antibiotic resistant strains, especially of extended-spectrum betalactamase producing strains (Souza Lopes et al. 2005), there has been renewed interest in Klebsiella infections.

According to the taxonomic classification of Orskov and Orskov (1984), the genus Klebsiella includes $K$. pneumoniae subsp. pneumoniae, K. pneumoniae subsp. ozaenae, $K$. pneumoniae subsp. rhinoscleromatis, $K$. oxytoca, $K$. terrigena, $K$. planticola and $K$. ornithinolytica. Clinically, $K$. pneumoniae is the most important species, accounting for about $95 \%$ of Klebsiella strains isolated from clinical specimens. $K$. pneumoniae subsp. pneumoniae is usually referred to as $K$. pneumoniae and the other two subspecies as $K$. ozaenae and $K$. rhinoscleromatis (Podschun \& Ullmann 1998). Recent phylogenetic studies have demonstrated heterogeneity within the genus Klebsiella and suggested its division into two genera, with the genus Raoultella being proposed for species previously called $K$. planticola, $K$. terrigena and K. ornithinolytica (Drancourt

Financial support: FACEPE and PROPESQ-UFPE

${ }^{+}$Corresponding author: catarina.lopes@uol.com.br

Received 19 April 2007

Accepted 1 October 2007 et al. 2001). Other phylogenetic analyses using RAPD, sequencing of gyrA and parC genes and automated ribotyping, have revealed that $K$. pneumoniae isolates fell into three clusters, $K$. oxytoca isolates fell into two clusters, while $K$. planticola isolates formed a sixth cluster (Brisse \& Verhoef 2001, Haeggman et al. 2004).

The characterization of $K$. pneumoniae usually includes phenotypic markers, like biochemical profile (Podschun \& Ullmann 1998), that often do not allowed to correct identification. Recently, a number of molecular based approaches to the identification of species of clinically important bacteria have been described. The sequencing of the $16 \mathrm{~S}$ rDNA gene represents the most precise method for the identification of Klebsiella species (Drancourt et al. 2001). Meanwhile, this is expensive and requires a high degree of technical competency to perform (Olive \& Bean 1999) and therefore not recommended for routine identification of bacteria. In contrast, PCR-based methods have been widely used for the analysis of the genetic diversity of many microorganisms (Agodi et al. 2000, Souza Lopes et al. 2005, Spacov et al. 2006). Depending on the primers and amplification conditions employed, the results allow discrimination of organisms at the genus, species or strain level. PCR ribotyping is a rapid technique that uses specific primers complementary to the 3 ' end of the $16 \mathrm{~S}$ rDNA gene and to the 5' end of the 23S rDNA gene to amplify intergenic spacer regions (ISRs). The ISRs are subject to lower evolutionary pressure, and therefore show a wider genetic variation (Gürtler \& Stanisich 1996). Variations 
in the length of the 16S-23S ISRs mainly depend on the number and type of tRNA genes and sequences for enzyme recognition, found within these regions (GarcíaMartínez et al. 1999).

Another highly promising method for bacterial identification is based on the PCR length polymorphisms of the intergenic spacers between tRNA genes (tDNAPCR). The tRNA genes are highly conserved among eubacteria and occur in multiple copies throughout the bacterial genome. These genes are generally clustered and are separated by spacers whose length and sequences are subjected to a higher degree of variations (Welsh \& McClelland 1992). The tDNA-PCR technique developed by Welsh and McClelland (1991) uses consensus primers complementary to the highly conserved edges of the flanking tRNA genes and which are directed outwardly.

The aim of the present study was to evaluate for the first time the potential of PCR ribotyping and tDNAPCR as tools for the identification of K. pneumoniae clinical isolates from different geographical origins in Brazil.

\section{MATERIALS AND METHODS}

Bacterial strains - All reference strains and clinical isolates analyzed in this study are listed in Table. The 43 clinical $K$. pneumoniae isolates analyzed were obtained from patients with different types of infection between March 1999 and January 2000, with 30 epidemiologically unrelated isolates collected from three public hospitals in the city of Recife, PE, 12 related isolates from a public hospital in the city of Maceió, AL, and one isolate from the city of Rio de Janeiro, Brazil. Two clinical isolates of E. aerogenes, from Recife, were also used for comparative analysis as this species shows a biochemical profile closely similar to $K$. pneumoniae, which may lead to identification errors.

Phenotypic characteristics - All clinical isolates were identified biochemically by the Mini API ID 32E systems (Bio Mérieux, Marcy l'Etoile, France) according to manufacturer's instructions. The isolates were stored in $15 \%$ glycerol at $-70^{\circ} \mathrm{C}$ and cultured in brain heart infusion broth (Difco, Detroit, MI, USA) for later molecular analysis.

TABLE

PCR ribotyping and tDNA-PCR patterns of the 45 clinical isolates of $K$. pneumoniae, E. aerogenes from Brazil, and six reference and type strains.

\begin{tabular}{|c|c|c|c|c|}
\hline Strains or clinical isolates ${ }^{a}$ & $\begin{array}{l}\text { Source of } \\
\text { isolation }\end{array}$ & City/State & $\begin{array}{l}\text { PCR ribotyping } \\
\text { pattern }\end{array}$ & $\begin{array}{l}\text { tDNA-PCR } \\
\text { pattern }\end{array}$ \\
\hline K. pneumoniae type strain (ATCC 13883) & - & - & R1 & $\mathrm{T} 1$ \\
\hline K. pneumoniae reference strain (ATCC 10031) & - & - & $\mathrm{R} 1$ & $\mathrm{~T} 1$ \\
\hline K. ozaenae reference strain (ATCC 25926) & Blood & - & $\mathrm{R} 1$ & $\mathrm{~T} 1$ \\
\hline $\begin{array}{l}\text { K. pneumoniae (K2-R, K11-R, K16-R, K19-R, } \\
\text { K20-R, K3-C, K5-C, K6-C, K8-C, K9-C, K10-C, } \\
\text { K11-C, K12-C, K15-C, K16-C, K17-C, K18-C) }\end{array}$ & Urine & Recife/PE & $\mathrm{R} 1$ & $\mathrm{~T} 1$ \\
\hline K. pneumoniae (K6-R, K10-R K13-R, K14-R) & Tracheal aspirate & Recife/PE & $\mathrm{R} 1$ & $\mathrm{~T} 1$ \\
\hline K. pneumoniae (K15-R) & Blood & Recife/PE & R1 & $\mathrm{T} 1$ \\
\hline K. pneumoniae (K17-R) & Tracheal aspirate & Recife/PE & R1 & $\mathrm{T} 2 \mathrm{a}$ \\
\hline K. pneumoniae (K18-R) & Urine & Recife/PE & $\mathrm{R} 1$ & $\mathrm{~T} 2 \mathrm{~b}$ \\
\hline K. pneumoniae (K21-I) & Feces & Recife/PE & $\mathrm{R} 1$ & $\mathrm{~T} 1$ \\
\hline K. pneumoniae (K22-I) & Blood & Recife/PE & $\mathrm{R} 1$ & $\mathrm{~T} 1$ \\
\hline K. pneumoniae (K4-C) & Wound & Recife/PE & $\mathrm{R} 1$ & $\mathrm{~T} 2 \mathrm{c}$ \\
\hline K. pneumoniae (K7-C) & Urine & Recife/PE & $\mathrm{R} 1$ & $\mathrm{~T} 3$ \\
\hline K. pneumoniae (K13-C and K14-C) & Wound & Recife/PE & $\mathrm{R} 1$ & $\mathrm{~T} 1$ \\
\hline $\begin{array}{l}\text { K. pneumoniae (P2204, P2205, P2206, P2207, } \\
\text { P2208, P2215, P2216, P2217, P2218, P2219, } \\
\text { P2220, P2221) }\end{array}$ & Not determinated & Maceió/AL & $\mathrm{R} 1$ & $\mathrm{~T} 1$ \\
\hline K. pneumoniae (P1298) & Cerebro-spinal fluid & Rio de Janeiro/RJ & $\mathrm{R} 1$ & $\mathrm{~T} 1$ \\
\hline $\begin{array}{l}\text { K. planticola ( } R \text {. planticola nov.) reference } \\
\text { strain (ATCC } 8329)\end{array}$ & - & - & $\mathrm{R} 2$ & $\mathrm{~T} 4$ \\
\hline K. oxytoca reference strain (CCT 0182) & - & - & $\mathrm{R} 3$ & $\mathrm{~T} 5$ \\
\hline E. aerogenes type strain (ATCC 13048) & Tracheal aspirate & - & $\mathrm{R} 4$ & T6 \\
\hline E. aerogenes (EA1-R) & Urine & Recife/PE & $\mathrm{R} 4 \mathrm{a}$ & T6 \\
\hline E. aerogenes (EA2-R) & Tracheal aspirate & Recife/PE & $\mathrm{R} 4 \mathrm{~b}$ & T6 \\
\hline
\end{tabular}

$a$ : Hospital da Restauração (-R); Instituto Materno Infantil de Pernambuco (-I); Hospital das Clínicas, Universidade Federal de Pernambuco (-C); ATCC: American Type Culture Collection; CCT: Coleção de Culturas Tropicais. 
DNA extraction - Genomic DNA was extracted from the isolates by the method described by Maniatis et al. (1982) and quantified by comparison with known amounts of lambda DNA digested with Hind III in 1\% agarose gel.

PCR ribotyping - The primers described by Kostman et al. (1992) were used for amplification of the spacers between the $16 \mathrm{~S}$ and $23 \mathrm{~S}$ rRNA genes. The primers (5'TTG TAC ACA CCG CCC GTC A -3' and 5'-GGT ACC TTA GAT GTT TCA GTT C-3') were designed based on the sequences complementary to the conserved regions of the $16 \mathrm{~S}$ and $23 \mathrm{~S}$ rRNA genes of various bacterial species.

The reactions were prepared in a total volume of $25 \mu \mathrm{l}$, containing 20 ng genomic DNA, 1 U Taq DNA polymerase (Gibco-BRL, Life Technologies, Gaithersburg, MD, USA), $0.16 \mathrm{mM}$ of each dNTP (Amersham-Pharmacia Biotech, USA), $1.5 \mathrm{mM} \mathrm{MgCl}_{2}, 20$ pmol of each primer in 1X PCR buffer. PCR was performed in a thermocycler (Hybaid) programmed for 30 cycles, with each cycle consisting of $1 \mathrm{~min}$ at $94^{\circ} \mathrm{C}, 1 \mathrm{~min}$ at $55^{\circ} \mathrm{C}$ and $1 \mathrm{~min}$ at $72^{\circ} \mathrm{C}$, with a final extension step for $7 \mathrm{~min}$ at $72^{\circ} \mathrm{C}$. A negative control without DNA was included and repeating the PCR three times tested reproducibility of the amplifications. The amplification products were submitted to $2 \%$ agarose gel electrophoresis in TBE buffer (0.089 M Tris-borate, $0.089 \mathrm{M}$ boric acid, $0.002 \mathrm{M}$ EDTA) at a constant voltage of $100 \mathrm{~V}$. The gels were stained with ethidium bromide, visualized under an ultraviolet transilluminator and photographed with a Polaroid camera. A 100-bp DNA marker (Biotools, B \& M Labs, Madrid, Spain) and a 100-bp DNA ladder (Invitrogen Co, Carlsbad, CA, USA) were used as molecular weight standard. $t D N A-P C R$ - The reaction was carried out with the outwardly directed consensus primers T3B (5'- AGG TCG CGG GTT CGAATC C - 3') and T5A (5'-AGT CCG GTG CTC TAA CCAACT GAC - 3') described by Welsh and McClelland (1991) and the PCR conditions have been described previously (Clementino et al. 2001). The amplified fragments detected in agarose gel were treated as discrete characters and recorded in a data matrix by scoring one for the presence and zero for the absence of a fragment. Similarity between strains was determined on the basis of the simple matching coefficient and the generated matrix was subjected to clustering by the unweighted pair group method with arithmetic means (UPGMA) (Grimont 1999). The Numerical Taxonomy System Program (NTSYS-PC, Applied Biostatistics, Inc.), version 1.30, was used in data analysis.

\section{RESULTS}

$P C R$ ribotyping - Electrophoretic analysis of the amplified products of the 16S-23S ISRs of $K$. pneumoniae ATCC 13883 and ATCC 10031 and K. ozaenae ATCC 25926 reference strains revealed identical patterns consisting of six bands with estimated sizes of $570,720,800,890,950$ and 1000 bp (Fig. 1A). This pattern differed from those individually obtained for the reference strains of $K$. oxytoca CCT 0182, K. planticola ATCC 8329 and E. aerogenes ATCC 13048.

The 43 clinical K. pneumoniae isolates from Recife, Maceió and Rio de Janeiro showed the same amplification pattern as that observed for the reference strains (Table). These results demonstrate that the primers described by Kostman et al. (1992) produced the same band pattern for all $K$. pneumoniae tested, both clinical isolates and reference strains (Fig. 1A). With respect to the
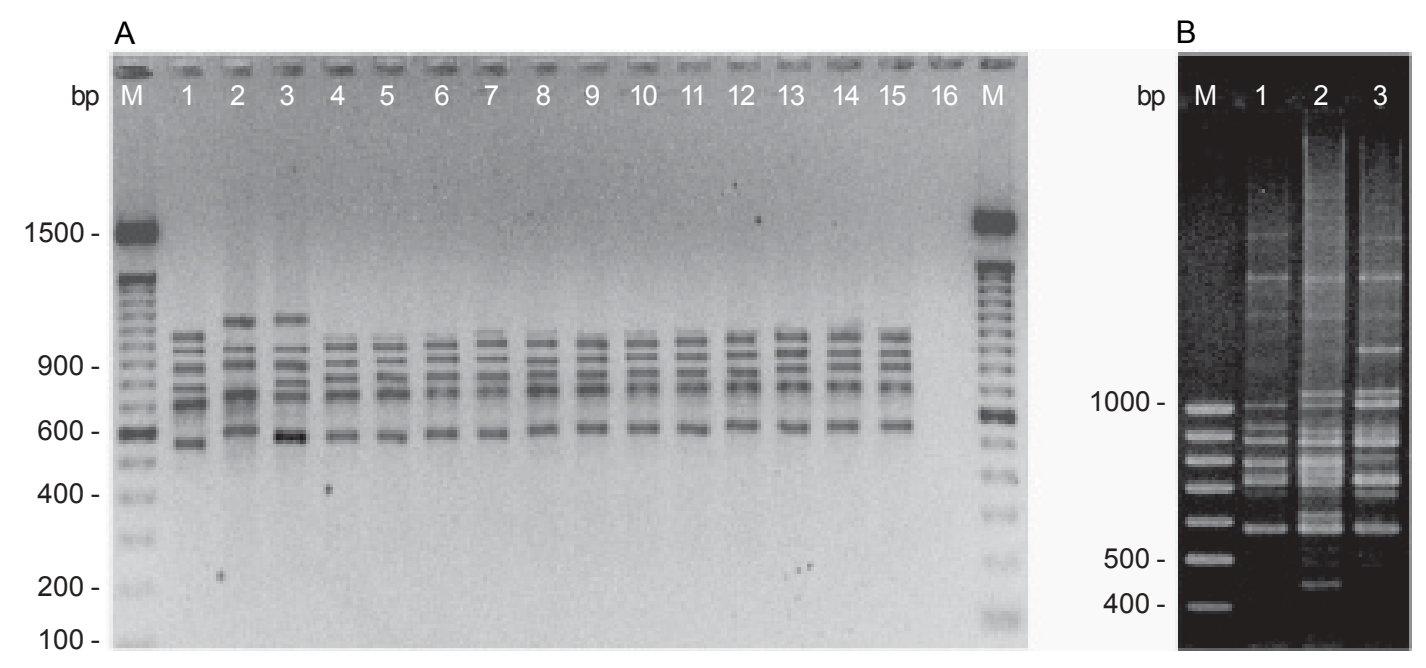

Fig. 1: PCR ribotyping patterns of Klebsiella and E. aerogenes strains. A: lanes - 1: E. aerogenes ATCC 13048; 2: K. planticola ATCC 8329; 3: K. oxytoca CTT 0182; 4: K. pneumoniae ATCC 13883; 5: K. pneumoniae ATCC 10031; 6: K. ozaenae ATCC 25926; 7 - 15: K. pneumoniae strains from Recife (K20R, K21-I, K22-I, K3-C, K4-C, K5-C, K6-C, K7-C and K8-C, respectively); 16: negative control with no added template DNA. B: lanes - 1: E. aerogenes ATCC 13048; 2-3: E. aerogenes (EA1-R and EA2-R). M: molecular size marker (100 bp). 
two clinical $E$. aerogenes isolates, both showed distinct amplification patterns that differed from those of the type strain (Fig. 1B). The electrophoretic patterns observed by PCR ribotyping were constant and reproducible, with identical profiles being obtained both after the three repetitions of the same sample and when using different batch of the same isolate.

tDNA-PCR - Identical tDNA-PCR patterns were obtained for K. pneumoniae ATCC 13883 and ATCC 10031 reference strains, with seven DNA fragments of 140, 200, $270,290,390,510$ and $580 \mathrm{bp}$ being detected. This pattern was identical to $K$. ozaenae ATCC 25926 reference strain, but differed from those observed for $K$. oxytoca CCT 0182, K. planticola ATCC 8329 and E. aerogenes
ATCC 13048 strains (Fig. 2A). It should be noted that both PCR-based methods used in the present study were not able to differentiate $K$. pneumoniae subspecies.

Five different amplification profiles (T1, T2a, T2b, T2c and T3) were identified by tDNA-PCR in the 43 clinical K. pneumoniae isolates from Brazil (Fig. 2C, Table), with $39(90,6 \%)$ showing banding patterns similar to K. pneumoniae reference strains ATCC 13883 and ATCC 10031 and $K$. ozaenae ATCC 25926 (pattern T1) (Fig. 2B). Three isolates from Recife fell into pattern $\mathrm{T} 2$ and were divided into three subtypes. The isolate K7C fell within pattern T3 (Fig. 2C). All K. pneumoniae isolates analyzed showed patterns distinct from those detected in $K$. oxytoca, $K$. planticola and $E$. aerogenes (Fig. 2A). The two clinical E. aerogenes isolates ana-
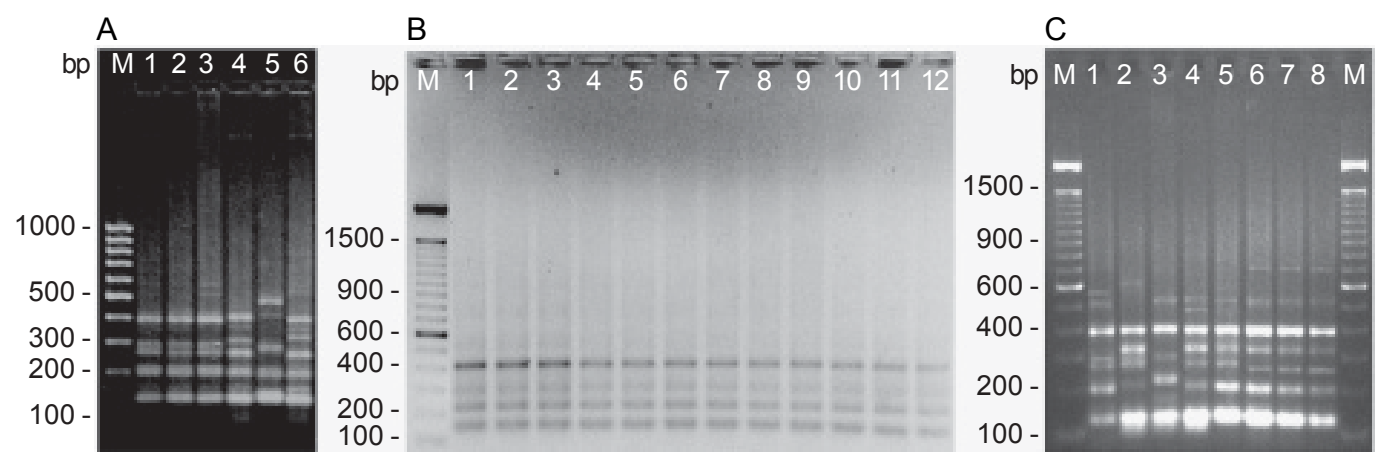

Fig. 2: tDNA-PCR patterns of Klebsiella and E. aerogenes strains. A: lanes - 1: K. pneumoniae ATCC 13883; 2: K. pneumoniae ATCC $10031 ; 3:$ K. ozaenae ATCC 25926; 4: K. oxytoca CTT 0182; 5: K. planticola ATCC 8329; 6: E. aerogenes ATCC 13048. B: lanes - 1: K. pneumoniae ATCC 13883, 2: K. pneumoniae ATCC 10031; 3: K. ozaenae ATCC 25926; 4-12: clinical isolates of K. pneumoniae K2-R, K6-R, K11-R, K13-R, K14-R, K15-R, K16-R, K19-R and K20-R (pattern T1). C: lanes - 1: K. pneumoniae ATCC 13883; 2- 5: K. pneumoniae strains showing amplification patterns T2c (K4-C), T3 (K7C), T2a (K17-R) and T2b (K18-R); 6: E. aerogenes ATCC 13048; 7 - 8: clinical isolates of E. aerogenes EA1-R and EA2-R. M: molecular size marker (100 bp).

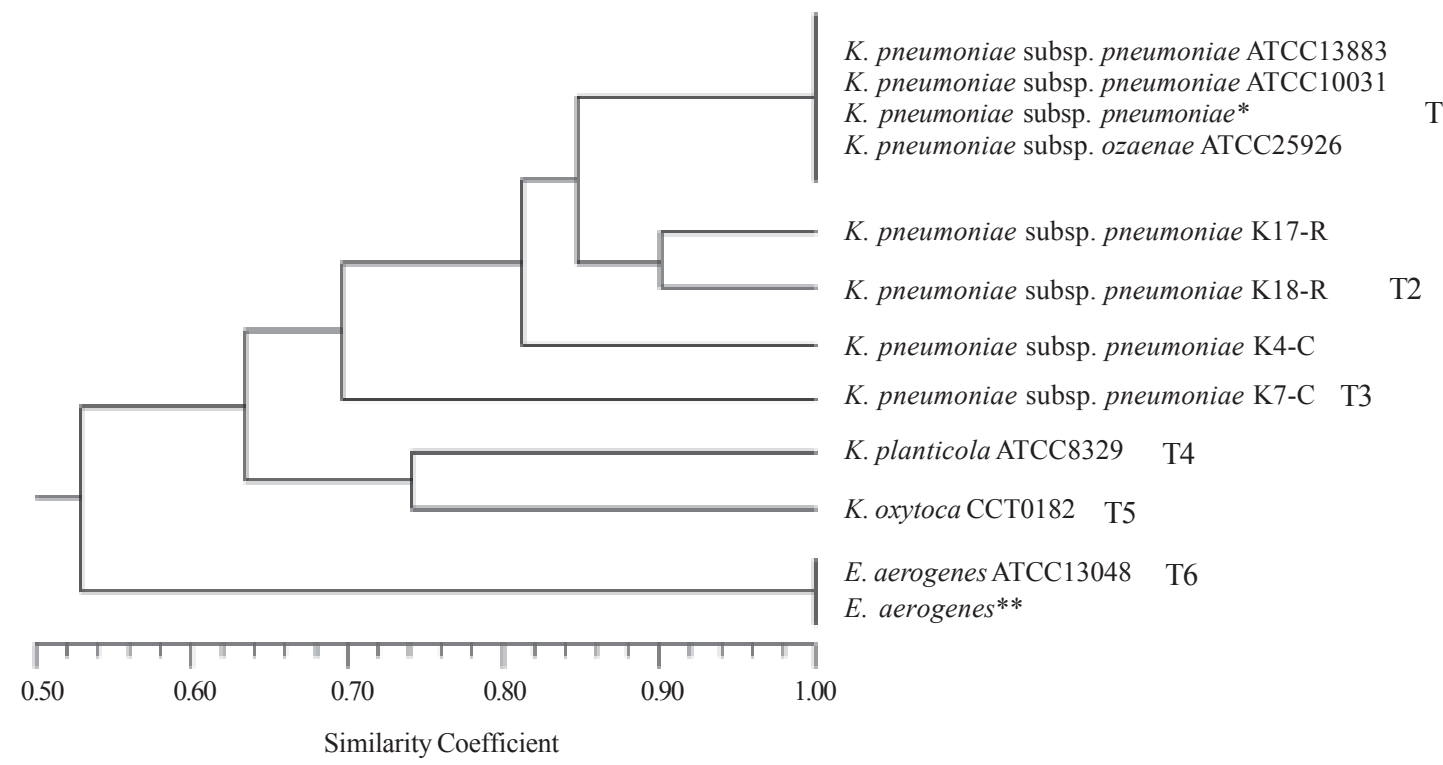

Fig. 3: dendrogram of tDNA-PCR patterns relatedness of clinical and reference strains of Klebsiella species and E. aerogenes generated with Simple Matching (SM) coefficient and the UPGMA clustering method. *: 39 clinical isolates of K. pneumoniae subsp. pneumoniae with band pattern T1; **: 2 clinical isolates of $E$. aerogenes; T1 to T6: tDNA-PCR patterns. 
lyzed showed the same pattern as the type strain but a distinct pattern compared to the other species (Fig. 2C).

The dendrogram obtained from the clustering analysis of the tDNA-PCR fingerprinting is reported in Figure 3. K. ozaenae ATCC 25926, K. pneumoniae ATCC 13883 and ATCC 10031 reference strains and $39 \mathrm{~K}$. pneumoniae clinical isolates clustering at $100 \%$ similarity and were grouped in pattern T1. The K. pneumoniae clinical isolates K17-R, K18-R and K4-C (pattern T2) which showed distinct band patterns from $K$. pneumoniae reference strains, clustering at $84 \%, 84 \%$ and $80 \%$, respectively, with K. pneumoniae ATCC 13883 . The isolate K7-C (pattern T3) showed $69 \%$ of similarity with ATCC 13883 . The dendrogram also showed that $K$. planticola and K. oxytoca were grouped in different patterns, with a similarity coefficient of $74 \%$. The species $K$. planticola appeared more closely related to $K$. oxytoca than to $K$. pneumoniae .

\section{DISCUSSION}

The identification of K. pneumoniae has been based on phenotypic methods such as biochemical profile analysis, which is time-consuming and often inconclusive since related species, like K. pneumoniae and $E$. aerogenes, frequently present similar biochemical patterns. Currently, the molecular methods that can be used to identify K. pneumoniae are sequencing of $r p o B$, gyrA and $\operatorname{par} C$ genes and $16 \mathrm{~S}$ rRNA region (Brisse \& Verhoef 2001, Drancourt et al. 2001). These methods are more complex and expensive than PCR based-methods.

To investigate the performance of PCR ribotyping and TDNA-PCR for identification of $K$. pneumoniae clinical isolates, these PCR methods were evaluated. No polymorphism was detected in the $16 \mathrm{~S}$ and $23 \mathrm{~S}$ ISRs among $K$. pneumoniae isolates from different geographical origins within Brazil, demonstrating that this species presents a specific PCR ribotyping pattern with the primers described by Kostman et al. (1992). Its amplification pattern differed from related species analyzed, showing that this technique is efficient for the molecular identification of $K$. pneumoniae isolates. In other reports, PCR ribotyping also did not show polymorphism of amplification patterns for different isolates of Pseudomonas aeruginosa (Agodi et al. 2000), Bacillus cereus (Daffonchio et al. 1998) and for various species of the genus Salmonella (Lagatolla et al. 1996), indicating that this method is efficient for the identification of these bacteria. On the other hand, isolates of Enterobacter cloacae (Clementino et al. 2001), and Staphylococcus aureus (Pereira et al. 2002), exhibit a high degree of polymorphism, and PCR ribotyping has therefore been indicated as a tool for the epidemiological study of these species.

The tDNA-PCR is useful for identifying microorganisms at species level. Most bacteria analyzed by this technique showed a single species-specific pattern (De Gheldre et al. 1999, Baele et al. 2000, Clementino et al. 2001). Therefore, some authors have emphasized the importance of tDNA-PCR as a tool for the identification of bacterial species. On the other hand, different profiles were detected by tDNA-PCR for S. aureus,
Staphylococcus haemolyticus (Maes et al. 1997), Bacillus licheniformis (Daffonchio et al. 1998) and $P$. aeruginosa (Spacov et al. 2006). In the present report tDNA-PCR allowed the discrimination of the clinical $K$. pneumoniae isolates from Brazil into three major patterns, with a predominance of the group that showed the same profile as the $K$. pneumoniae reference strains. The division of $K$. pneumoniae into three patterns suggests that this species consists of at least three different lineages as determined by tDNA-PCR, in agreement with recent reports in Europe (Brisse \& Verhoef 2001, Haeggman et al. 2004). Also based on tDNA-PCR analyses, K. pneumoniae subsp. ozaenae appeared closely related to $K$. pneumoniae subsp. pneumoniae. Moreover, whithin $K$. pneumoniae subsp. pneumoniae, the tDNA patterns observed here do not appear to correspond to the three taxonomic subspecies of $K$. pneumoniae. This was supported by tDNA-PCR analyses, as the reference strain for K. pneumoniae subsp. ozaenae revealed band patterns typical for pattern T1, like the majority of K. pneumoniae subsp. pneumoniae clinical isolates studied here. Futhermore, this was not due a misidentification of the four isolates that fell into patterns T2 and T3 since their biochemical characterization, by the Mini API ID 32E systems, revealed a profile typical for K. pneumoniae subsp. pneumoniae.

In the present study both tDNA-PCR and PCR ribotyping were efficient for the differentiation among $K$. pneumoniae, K. oxytoca, K. planticola and E. aerogenes reference strains, but could not differentiate K. pneumoniae subspecies. Brisse and Verhoef (2001) showed that de gyrA and $\operatorname{parC}$ sequence analysis also could not differentiate $K$. pneumoniae subspecies, but automated ribotyping with $M l u \mathrm{I}$ could distinguish their three subspecies. On the other hand, the low variability in the 16S rRNA locus had been noted sometimes as an impediment in using $16 \mathrm{~S}$ rRNA gene sequencing to discriminate Klebsiella at the genus and/or species level (Boye $\&$ Hansen 2003). The discriminative power of PCR ribotyping and tDNA-PCR for Klebsiella species were at the first time evaluated by this work, using both reference and wild strains. Although a PCR fingerprint will generally have less information than comparing the DNA sequence of a specific region in each organism, the reference strains of the four Klebsiella species tested showed clearly different ribotyping and tDNA-PCR patterns, demonstrating that these two methods are reliable for differentiation of the species within the genus Klebsiella.

The identification method may has high discrimination power and good reproducibility, the complexity of the method and interpretation of results as well as the costs involved in setting up and using the method may be beyond the capabilities of the laboratory. The PCR basedmethods used in this work showed ease of implement and interpretation, low cost and good reproducibility and discrimination power. Additionally, they use universal primers that can type others bacteria species.

While tDNA-PCR demonstrated a genetic diversity between K. pneumoniae strains resulted of point mutations or rearrangements detected by scoring band presence versus absence in banding patterns in the DNA am- 
plification procedures, PCR ribotyping showed a conserved and reprodutible PCR ribotype pattern suggesting being a suitable alternative method to conventional biochemical identification procedures for reliable identification of this microrganism.

\section{ACKNOWLEDGMENTS}

To the Microorganisms Collection of the Oswaldo Cruz Foundation, INCQS-Fiocruz, Rio de Janeiro, Brazil, for kindly providing the reference strains. To the Laboratory of Bacteriology, HOC, Universidade de Pernambuco, for the use of miniAPI automated system.

\section{REFERENCES}

Agodi A, Sciacca A, Campanile F, Messina C, Barchitta M, Sciacca S, Stefani S 2000. Molecular epidemiology of Pseudomonas aeruginosa from cystic fibrosis in Sicily: genome macrorestriction analysis and rapid PCR-ribotyping. New Microbiol 23: 319-327.

Baele M, Baele P, Vaneecoutte M, Storms V, Butaye P, Devriese LA, Verschraegen G, Gillis M, Haesebrouck F 2000. Application of tRNA intergenic spacer PCR for identification of Enterococcus species. J Clin Microbiol 38: 4201- 4207.

Boye K, Hansen DS 2003. Sequencing of 16S rDNA of Klebsiella: taxonomic relations within the genus and to other Enterobacteriaceae. Int J Med Microbiol 292: 495-503.

Brisse S, Verhoef J 2001. Phylogenetic diversity of Klebsiella pneumoniae and Klebsiella oxytoca clinical isolates revealed by randomly amplified polymorphic DNA, gyrA and parC genes sequencing and automated ribotyping. Int J Syst Evol Microbiol 51: 915-924.

Clementino MM, Filippis I, Nascimento CR, Branquinho R, Rocha CL, Martins O 2001. PCR analysis of tRNA intergenic spacer, 16S-23S internal transcribed spacer, and randomly amplified polymorphic DNA reveal inter- and intraspecific relationships of Enterobacter cloacae strains. J Clin Microbiol 39: 3865-3870.

Daffonchio D, Borin S, Giuseppe F, Manachini PL, Sorlini C 1998. PCR fingerprinting of whole genome: the spacers between the $16 \mathrm{~S}$ and 23S rRNA genes and of intergenic tRNA gene regions reveal a different intraspecific genomic variability of Bacillus cereus and Bacillus licheniformis. Int J Syst Bacteriol 48: 107-116.

De Gheldre Y, Vandamme P, Gooses H, Struelens MJ 1999. Identification of clinically relevant viridans streptococci by analysis of transfer DNA intergenic spacer length polymorphism. Int J Syst Bacteriol 49: 1591-1598.

Drancourt M, Bollet C, Carta A, Rousselier P 2001. Phylogenetic analyses of Klebsiella species delineate Klebsiella and Raoultella gen. nov., with description of Raoultella ornithinolytica comb. nov., Raoultella terrigena comb. nov., Raoultella planticola comb. nov. Int J Syst Evol Microbiol 51: 925-932.

García-Martínez J, Acinas SG, Antón AI, Rodríguez-Valera F 1999. Use of the 16S-23S ribosomal genes spacer region in studies of prokaryotic diversity. J Microbiol Meth 36: 55-64.
Grimont PAD 1999. Taxonomy and classification of bacteria. In PR Murray, EJ Baron, MA Pfaller (eds), Manual of Clinical Microbiology, American Society of Microbiology, Washington, p. 251-252.

Gürtler V, Stanisich A 1996. New approaches to typing and identification of bacteria using the $16 \mathrm{~S}-23 \mathrm{~S}$ rDNA spacer region. Microbiol 142: 3-6.

Haeggman S, Lofdahl S, Paauw A, Verhoef J, Brisse S 2004. Diversity and evolution of the class A chromosomal betalactamase gene in Klebsiella pneumoniae. Antimicrob Agents Chemother 48: 2400-2408.

Kostman JR, Edlind TD, LiPuma JJ, Stull TL 1992. Molecular epidemiology of Pseudomonas cepacia determined by polymerase chain reaction ribotyping. J Clin Microbiol 30: 20842087.

Lagatolla C, Dolzani L, Tonin E, Lavenia A, Michelle M, Tommasini T, Monti-Bragadin C 1996. PCR ribotyping for characterizing Salmonella isolates of different serotypes. $J$ Clin Microbiol 34: 2440-2443.

Maes N, De Gheldre Y, De Ryck R, Vaneechoutte M, Meugnier H, Etienne J, Struelens MJ 1997. Rapid and accurate identification of Staphylococcus species by tRNA intergenic spacer length polymorphism analysis. J Clin Microbiol 35 : 2477-2481.

Maniatis T, Fritsch EF, Sambrook J 1982. Molecular cloning. A laboratory manual, 2nd ed., Cold Spring Laboratory Press, New York.

Olive DM, Bean P 1999. Principles and applications of methods for DNA-based typing of microbial organisms. J Clin Microbiol 37: 1661-1669.

Orskov I, Orskov F 1984. Serotyping of Klebsiella pneumoniae. Methods Microbiol 14: 143-164.

Pereira MSV, Leal NC, Leal TCA, Sobreira M, Almeida AMP, Siqueira-Júnior JP, Campos-Takaki GM 2002. Typing of human and bovine Staphylococcus aureus by RAPD-PCR and ribotyping-PCR. Lett Appl Microbiol 35: 32-36.

Podschun R, Ullmann U 1998. Klebsiella spp. as nosocomial pathogens: epidemiology, taxonomy, typing methods, and pathogenicity factors. Clin Microbiol Rev 11: 589-603.

Souza Lopes AC, Rodrigues JF, Morais Júnior MA 2005. Molecular typing of Klebsiella pneumoniae isolates from public hospitals in Recife, Brazil. Microbiol Res 160: 37-46.

Spacov ICG, Silva SAM, Morais Júnior MA, Morais MA 2006. Polymorphism of the rDNA and tDNA loci in clinical isolates of Pseudomonas aeruginosa: A perspective for molecular epidemiology surveillance. Genetics Mol Biol 29: 722-729.

Welsh J, McClelland M 1991. Genomic fingerprints produced by PCR with consensus tRNA gene primers. Nucleic Acids Res 19: 861-866.

Welsh J, McClelland M 1992. PCR-amplified length polymorphisms in tRNA intergenic spacers for categorizing staphylococci. Mol Microbiol 6: 1673-168. 